Article

\title{
Thermal Performance of Motor and Inverter in an Integrated Starter Generator System for a Hybrid Electric Vehicle
}

\section{Sung Chul Kim}

Green Car Power System R\&D Division, Korea Automotive Technology Institute, 74 Yongjung-Ri, Pungse-Myun, Dongnam-Gu, Chonan-Si, Chungnam 330-912, Korea; E-Mail: sckim@katech.re.kr; Tel.: +82-41-559-3093; Fax: +82-41-559-3235

Received: 13 September 2013; in revised form: 5 November 2013 / Accepted: 15 November 2013 / Published: 22 November 2013

\begin{abstract}
If the integrated starter generator (ISG) motor and inverter operate under continuously high loading conditions, the system's performance and durability will decrease and the heat dissipation requirements will increase. Therefore, in this study, we developed two cooling designs for the ISG motor and inverter, and then carried out both a model analysis and an experiment on the fluid flow and thermal characteristics of the system under various operating conditions. As the outdoor temperature increased from $25^{\circ} \mathrm{C}$ to $95^{\circ} \mathrm{C}$, the coil temperature of the air-cooled motor increased by about $82{ }^{\circ} \mathrm{C}$. Under the harsh-air condition of $95{ }^{\circ} \mathrm{C}$, the coil of the air-cooled motor increased to a maximum temperature of about $158.5^{\circ} \mathrm{C}$. We also determined that the temperature of the metal-oxide-semiconductor field-effect transistor (MOSFET) chip in the liquid-cooled inverter increased to a maximum temperature of about $96.8^{\circ} \mathrm{C}$ under a coolant flow rate of $4 \mathrm{~L} / \mathrm{min}$ and a coolant temperature of $65^{\circ} \mathrm{C}$. The observed thermal performance of the ISG motor and inverter using the proposed cooling structures was found to be sufficient for heat loads under various real driving conditions for a hybrid electric vehicle (HEV).
\end{abstract}

Keywords: thermal performance; integrated starter generator; motor; inverter; heat dissipation; cooling structure

\section{Nomenclature:}

$B \quad$ magnetic flux density (T)

$f \quad$ frequency $(\mathrm{Hz})$

I phase current $\left(\mathrm{A}_{\text {rms }}\right)$

$I_{\text {on }} \quad$ on-current at metal-oxide-semiconductor field-effect transistor

(MOSFET) (A $\left.\mathrm{A}_{\mathrm{rms}}\right)$ 
$k_{e} \quad$ eddy current coefficient

$k_{h} \quad$ hysteresis coefficient

$L \quad$ length of busbar (m)

$P_{\text {busbar }} \quad$ conduction loss at busbar (W)

$P_{\text {copper }} \quad$ copper loss at coil (W)

$P_{\text {iron }} \quad$ iron loss at core $(\mathrm{W})$

$P_{e} \quad$ eddy current loss (W)

$P_{h} \quad$ hysteresis loss (W)

$P_{\text {switch }} \quad$ switching loss at MOSFET (W)

$P_{s(o n)} \quad$ switching loss at rising time (W)

$P_{s(o f f)} \quad$ switching loss at falling time (W)

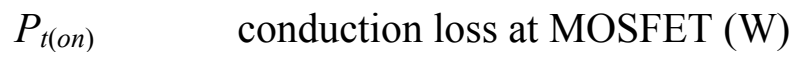

$R_{\text {busbar }} \quad$ busbar resistance $(\Omega)$

$R_{\text {coil }} \quad$ coil resistance $(\Omega)$

$S \quad$ cross sectional of busbar $\left(\mathrm{m}^{2}\right)$

$T_{\text {fric }} \quad$ friction torque $(\mathrm{Nm})$

$t_{s(o n)} \quad$ turn on time of MOSFET (s)

$t_{r i} \quad$ current rising time (s)

$t_{f v} \quad$ voltage falling time (s)

$t_{s(o f f)} \quad$ turn off time of MOSFET (s)

$t_{f i} \quad$ current falling time (s)

$t_{r v} \quad$ voltage rising time (s)

$t_{o n} \quad$ conduction time of MOSFET per pulse (s)

$V_{\text {off }} \quad$ off time voltage (V)

$V_{\text {on }} \quad$ on time voltage $(\mathrm{V})$

$\rho \quad$ specific resistance $(\Omega \mathrm{m})$

$\omega \quad$ angular frequency $(\mathrm{rad} / \mathrm{s})$

Abbreviations:

CFD computational fluid dynamics

FEA finite element analysis

HEV hybrid electric vehicle

IGBT insulated gate bipolar transistor

ISG integrated starter generator

MOSFET metal-oxide-semiconductor field-effect transistor

MRF multiple reference frame

PCB printed circuit board 


\section{Introduction}

There is an increasing demand for more efficient and higher performing internal combustion engines and hybrid electric vehicles (HEVs) because of climate change caused by the extensive use of carbon fuels and the large amount of greenhouse gases in the atmosphere. To meet this demand, various electrical systems have been embedded in automobiles, and the fuel efficiency of internal combustion engines and HEVs has been improved. Integrated starter generator (ISG) systems are among these improvements [1,2]. An ISG in a HEV is a component that regulates both the starter motor and the generator, which stops the engine when the car stops by activating the idle stop-and-go function. This reduces the fuel consumption by collecting energy through regenerative braking [3]. To maximize the efficiency of the ISG, the motor must be matched with an inverter, which is crucial for determining the performance of the ISG [4].

Motors and inverters generate large amounts of heat when a car uses a large amount of electricity when starting the engine or a long duration of generating use. Because this reduces the performance of the ISG or prevents it from operating properly, a temperature limit is required to control driving with the ISG system. Such heat management is increasingly important in electronics equipment as there has been an increased demand for HEVs that are more efficient and have smaller combustion engines and other car parts.

The proposed system in this study is the belt-driven ISG system with a $42 \mathrm{~V}$ interior permanent magnet synchronous motor (IPMSM). The IPMSM uses the rare earth magnet, and it has the characteristics such as higher efficiency and wider operating speed range. The IPMSM was designed for eight-pole with 36 stator slots and generating about $5 \mathrm{~kW}$. On the other hand, Xue et al. [5] studied on the belt-driven ISG system with a $42 \mathrm{~V}$ induction motor that is lower efficiency than the IPMSM. The induction motor was designed for the four-pole with 36 stator slots and generating $3-4 \mathrm{~kW}$. In addition, the IPMSM is cooled by forced air flow unlike the induction motor with liquid-cooled design.

The following studies were conducted to develop efficient heat management techniques for motors and inverters, which are key components in electric vehicles (EVs). Kimotho et al. [6] improved the thermal performance up to $15 \%$ based on the end winding temperature, by applying housing fin shapes to a blushless direct current permanent magnet motor via computational fluid dynamics (CFD) analysis. $\mathrm{Li}$ [7] analyzed the fluid movement by altering the angles of the cooling fan blades that are equipped in an electric motor, and determined an optimal motor cooling design from the cooling flow rate and the fan efficiency.

Inverters, which control motors, must have sufficiently high power densities. Because the heat generated from inverters differ depending on the inverter materials and the cooling structure, many studies on inverters are carried out in addition to studies on motors. Mallik et al. [8] introduced various thermal management materials that can be used for the electronic control unit of power electronics for cars. They also contrasted the types and features of the housing and thermal interface materials (TIMs), which are crucial design factors affecting heat dissipation. Regarding power electronics for vehicles, Bennion et al. [9] developed a method for predicting the thermal models according to the changes in the thermal condition of the power module through finite element analysis (FEA). Chen et al. [10] assessed the thermal performance by analyzing the temperature distribution and heat resistance based the layered structure of the power electronics in automobiles. Because the power electronics have a 
water cooling system with a higher power density, the thermal performance changed drastically depending on the coolant flow and the cooling channels in the cold plate.

Thermal management studies generally focus on a typical HEV/EV traction motor or inverter. Because ISG motors and inverters are different from existing traction motors and inverters in terms of the driving conditions, a new analysis of the thermal characteristics must be conducted. A typical ISG system is represented by the schematic in Figure 1. In HEVs, the ISG which functions as both a starter and a generator is attached to the engine with a belt. An inverter supplies electricity to the ISG motor by converting direct current (DC) from batteries into alternating current (AC). This paper identifies the heat transfer characteristics of the ISG system by analyzing the heat and fluid flows with respect to the driving conditions of the motor, which is a HEV $42-\mathrm{V} / 5-\mathrm{kW}$ belt-driven ISG motor, and prototypes of the inverter. This paper also analyzes the cooling design and suggests how to improve the thermal performance based on the assessments of simplified analysis models.

Figure 1. Schematic diagram of a $42 \mathrm{~V}$ integrated starter generator (ISG) system in hybrid electric vehicles (HEVs) [11]. ICE: internal combustion engine; ECU: electronic control unit.

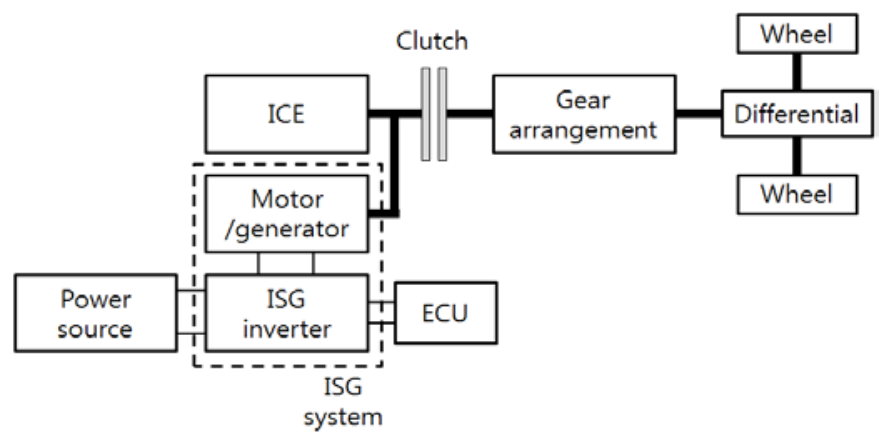

\section{Design and Numerical Analysis}

\subsection{Air-Cooled Motor}

As shown in Figure 2, an ISG motor is composed of a rotor unit, which includes a rotor core, permanent magnet, and shaft; and a stator unit, which includes a stator core and coil.

Figure 2. Analysis model of ISG motor.




The housing (flange and bracket) is installed at both ends of the motor to protect the cooling fans, bearings and resolver parts; they also serve as a heat sink. A centrifugal fan in the housing spins with the motor and generates a forced air flow to mitigate the heat. The motor model for this study eliminated some factors, such as the hole, gap and shape, which are unnecessary for analyzing heat and fluid flow. A total of approximately two million grids were used because the behavior of the flow is complex in the air gap between the stator and rotor cores, which is only $0.5 \mathrm{~mm}$. In addition, this study uses prism grids in the areas with fluid behavior, i.e., on the surface of the motor, for a more accurate analysis.

The governing equations of mass, momentum, and energy conservation were employed to analyze the heat and fluid flows of an ISG motor. The modified production $\mathrm{k}-\varepsilon$ model, modified from the Kato-Launder model, was used for the turbulence flow. This revised model corrected the excessive measures around the stagnation point in the standard k- $\varepsilon$ model. Commercial CFD software, SC/Tetra, (Software Cradle Co. Ltd., Osaka, Japan) was used to analyze this [12]. The normal temperature was set to $25{ }^{\circ} \mathrm{C}$, and the maximum temperature in the engine room of a hybrid car was set to $95{ }^{\circ} \mathrm{C}$. Based on the experimental environment of a motor dynamo, the motors installed in jigs were examined and compared with each other.

This study was carried out based on the hypotheses that the air flow surrounding the ISG motor exhibits an incompressible turbulence flow in a three-dimensional (3D), steady-state condition, and the material properties of the motor parts are the same regardless of the temperature. The amount of heat generated from the motors was measured using MotorPro (Komotek, Sungnam, Korea), a software program that analyzes and assists the design of electric motors. This software combines a design method, which is composed of design theories, accumulated experiences, statistics, and experiments, with finite elements methods [13]. In motors, three types of losses occur: copper loss caused by the current in the coil [Equation (1)], losses in the core caused by the changes in the magnetic flux density [Equation (2)], and mechanical losses caused by friction and flow resistance in a high-speed motor [Equation (3)]:

$$
\begin{gathered}
P_{\text {copper }}=3 \times R_{\text {coil }} \times I^{2} \\
P_{\text {core }}=P_{h}+P_{e}=k_{h} f B^{n}+k_{e} f^{2} B^{2} \\
P_{\text {mech }}=T_{\text {fric }} \times \omega
\end{gathered}
$$

Under harsh high-temperature conditions, the changes caused by the increased temperatures were taken into account to measure the copper and core losses. However, because mechanical losses are due to friction losses more than wind losses caused by the moving parts, the temperature changes were not taken into account to measure this type of loss. As shown in Figure 3, the motor speed in the electricity generation mode was designed to use a continuous output of $7000 \mathrm{rpm}$ at the point of maximum power, which is equivalent to an engine speed of $2800 \mathrm{rpm}$ with a ratio of an ISG pulley to an engine pulley of $2.5: 1$.

Table 1 lists the boundary conditions and the amount of heat generated, which are used to analyze heat and fluid flows in the ISG motor. 
Figure 3. T-N curve under the generating mode of ISG motor.

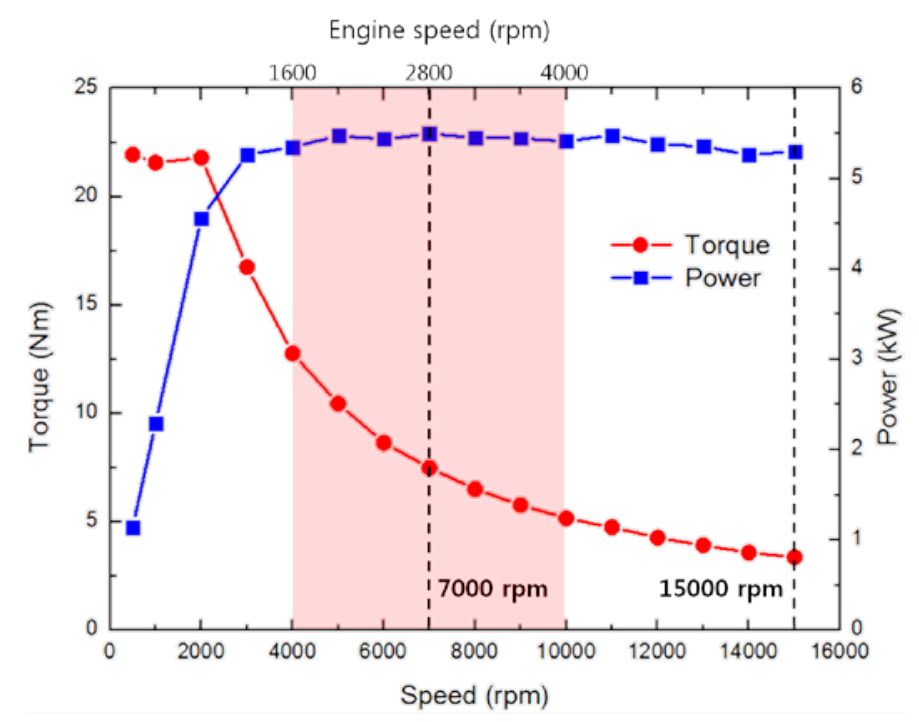

Table 1. Boundary conditions. MOSFET: metal-oxide-semiconductor field-effect transistor.

\begin{tabular}{|c|c|c|}
\hline Items & Components & Conditions \\
\hline Ambient temp. $\left({ }^{\circ} \mathrm{C}\right)$ & \multirow{4}{*}{ Motor } & $25 *, 95$ \\
\hline Ambient pressure $(\mathrm{Pa})$ & & 101,325 \\
\hline Motor speed (rpm) & & $7000 *, 15,000$ \\
\hline Motor torque $(\mathrm{Nm})$ & & $7.5 *, 3.6$ \\
\hline Inverter current $\left(\mathrm{A}_{\mathrm{rms}}\right)$ & \multirow{3}{*}{ Inverter } & 150 \\
\hline Coolant flow rate $(\mathrm{L} / \mathrm{min})$ & & $2,4 *, 6$ \\
\hline Coolant inlet temp. $\left({ }^{\circ} \mathrm{C}\right)$ & & $45,55,65 *$ \\
\hline \multirow{5}{*}{ Heat source (W) } & Coil & 450.6*,450.6 (@15,000 rpm),583.5 (@95 ㄷ) \\
\hline & Stator core & 16.4*,212.9(@15,000 rpm),17.2(@95C $)$ \\
\hline & Bearing & $46.5 *, 145.7(@ 15,000 \mathrm{rpm}), 46.5\left(@ 95^{\circ} \mathrm{C}\right)$ \\
\hline & MOSFET & 179.7 \\
\hline & Busbar & 5.5 \\
\hline
\end{tabular}

*: Standard condition.

To mimic this circulation to evaluate motor parts, including cooling fans, the multiple reference frame (MRF) method with the moving wall condition were used. In the MRF method, the flow region surrounding the moving parts was split into spinning and non-spinning parts according to a rotational effect by creating a virtual rotation volume. Simple-shaped cylinders, such as rotor cores and shafts, exhibited rotation using the moving wall condition. Stators and outer walls were analyzed with the stationery wall condition. For the convergence of dependent variables in repetitive calculations of the continuity, momentum, turbulence, and energy equations, the maximum value of relative error was set to below $10^{-6}$.

\subsection{Liquid-Cooled Inverter}

As shown in Figure 4a, the design model of the ISG inverter is composed of a power module and a cold plate, and the power module has 24 metal-oxide-semiconductor field-effect transistors (MOSFETs). 
The MOSFETs enable heat dissipation through the cold plates via the coolant in the cooling channel. The coolant was assumed to be a 50\%/50\% mixture of water and ethylene glycol with physical properties based on [14]. The MOSFET used for this study was the IRFS3107 model (International Rectifier, El Segundo, CA, USA) that included a three-phase circuit aligned with a parallel connection of four tops and four bottoms to increase the current capacity. This study used the MOSFET package to design a module, and we chose a metal printed circuit board (PCB) to include the effects of temperature changes. The PCB has a thickness of $2 \mathrm{~mm}$ to evaluate the heat generation characteristics.

The MOSFET package was modeled through a tool provided by FloTHERM (Mentor Graphics Corporation, Wilsonville, OR, USA) [15], a thermal analysis code for electronics devices. FloTHERM is a finite-volume-based software package that uses simple Cartesian grid meshing. It has a 3D solver for the Navier-Stokes equations and is equipped with built-in boundary conditions for common heat transfer devices and a capability to incorporate turbulent flow viscosity losses. By restricting the model to Cartesian grid meshing, the convergence may be enhanced, generating a larger grid density [16]. To embody the characteristics of heat conduction, the model was designed to include the detailed lamination structure of the metal PCB. These details are shown in Figure $4 \mathrm{~b}$.

Figure 4. Analysis model of ISG inverter: (a) power module and cold plate; (b) MOSFET package and metal printed circuit board (PCB).

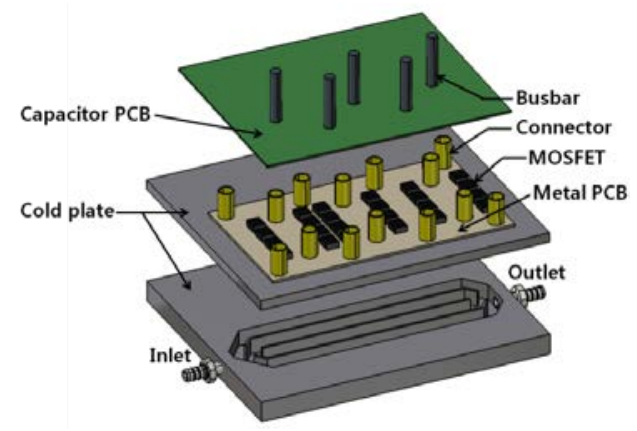

(a)

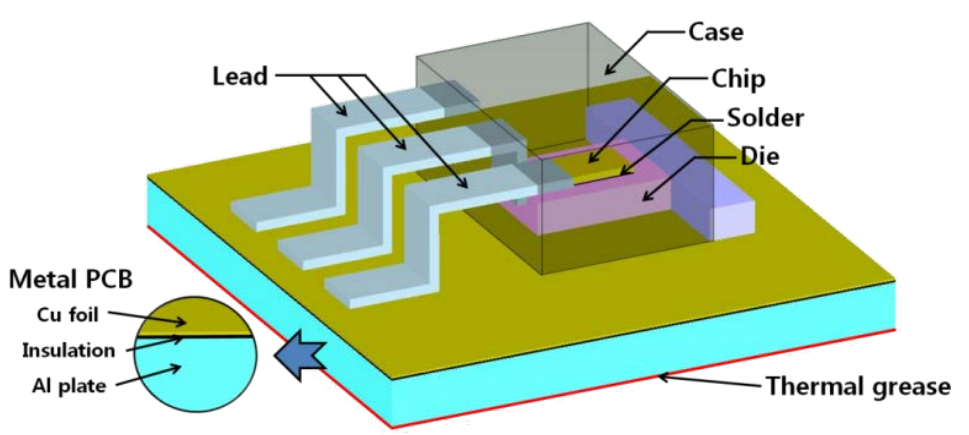

(b)

The amount of heat generation and the material properties of the components of the ISG inverter under driving conditions were used as the input values. The boundary conditions and the size and material properties are listed in Tables 1 and 2 in detail, respectively.

As shown in Table 1, the standard condition for the ISG inverter was set to enable the coolant at $65{ }^{\circ} \mathrm{C}$ to be supplied at a rate of $4 \mathrm{~L} / \mathrm{min}$. The coolant temperature and flow rate according to the heat load were modified from $45{ }^{\circ} \mathrm{C}$ to $65^{\circ} \mathrm{C}$ and from $2 \mathrm{~L} / \mathrm{min}$ to $6 \mathrm{~L} / \mathrm{min}$, respectively. Regarding the amount of heat generated, the inverter losses used are determined from the values when a current of $150 \mathrm{~A}$ is generated using the rated condition of an ISG motor speed of $7000 \mathrm{rpm}$. As shown in Figure 5, a MOSFET with a high switching frequency of $16 \mathrm{kHz}$ can have overlapping sections with the current and the voltage at the switching transient sections, resulting in a switching loss [Equations (4)-(6)] [17]. The conduction loss, which is caused by a resistance during the flow of current inside a MOSFET $\left(t_{o n}\right)$ when the switch is open, is a major loss along with the switching loss of a MOSFET [Equation (7)] [17]. The conduction loss at a busbar was calculated using the current value and the busbar resistance [Equation (8)] [17]. 


$$
\begin{gathered}
P_{\text {switch }}=P_{s(o n)} \times P_{s(o f f)} \\
P_{s(o n)}=0.5 \times V_{o f f} \times I_{o n} \times t_{s(o n)} \times f \\
P_{s(o f f)}=0.5 \times V_{o f f} \times I_{o n} \times t_{s(o f f)} \times f \\
P_{\text {conduction }}=V_{o n} \times I_{o n} \times t_{o n} \times f \\
P_{\text {busbar }}=I^{2} \times R, R=\rho \frac{L}{S}
\end{gathered}
$$

Dense grids are installed around key parts such as MOSFETs, busbars and cold plates for more

\begin{tabular}{|c|c|c|c|c|c|c|}
\hline \multicolumn{2}{|c|}{ Part name } & No. & Size $\left(\mathbf{m m}^{3}\right)$ & $\begin{array}{l}\text { Density } \\
\left(\mathrm{kg} / \mathrm{m}^{3}\right)\end{array}$ & $\begin{array}{c}\text { Specific heat } \\
\left(\mathrm{J} / \mathrm{kg}^{\circ} \mathrm{C}\right)\end{array}$ & $\begin{array}{c}\text { Thermal conductivity } \\
(\mathrm{W} / \mathrm{m} \mathbf{K})\end{array}$ \\
\hline \multirow{6}{*}{ MOSFET } & Package & \multirow{6}{*}{24} & $15.2 \times 10.2 \times 4.45$ & - & - & - \\
\hline & Chip & & $3.3 \times 1.81 \times 0.25$ & 2330 & 700 & 117 \\
\hline & Solder & & $3.3 \times 1.81 \times 0.025$ & 1450 & 134 & 50 \\
\hline & Die & & $5.3 \times 3.81 \times 1.27$ & 1000 & 1000 & 271 \\
\hline & Lead & & $6.23 \times 1.46 \times 2.9$ & 893 & 130 & 188 \\
\hline & Case & & $9.0 \times 10.2 \times 4.45$ & 2300 & 106 & 0.8 \\
\hline \multirow{3}{*}{ Metal PCB } & $\mathrm{Cu}$ foil & \multirow{3}{*}{1} & $197 \times 113 \times 0.07$ & 8930 & 385 & 385 \\
\hline & Insulation & & $197 \times 113 \times 0.08$ & 1200 & 880 & 0.3 \\
\hline & Al plate & & $197 \times 113 \times 1.85$ & 2700 & 963 & 180 \\
\hline \multicolumn{2}{|c|}{ Capacitor PCB } & 1 & $150 \times 200 \times 1.6$ & 1200 & 880 & 0.3 \\
\hline \multicolumn{2}{|c|}{ Busbar } & 5 & $4 \times 4 \times 52$ & 8930 & 385 & 385 \\
\hline \multicolumn{2}{|c|}{ Connector } & 14 & $6 \times 6 \times 22$ & 8930 & 385 & 385 \\
\hline \multicolumn{2}{|c|}{ Thermal grease } & 1 & $197 \times 113 \times 0.05$ & 2490 & 800 & 3.8 \\
\hline \multicolumn{2}{|c|}{ Cold plate } & 1 & $236 \times 200 \times 8$ & 2700 & 963 & 180 \\
\hline \multicolumn{2}{|c|}{ Inverter cover } & 1 & $220 \times 200 \times 82$ & 1200 & 420 & 0.25 \\
\hline
\end{tabular}
accurate analysis in the inverter analysis modeling. The number of mesh is about two million and the computational time required was about $10 \mathrm{~h}$. The computations are stopped when the sum of the absolute values of the residuals for temperature and velocity are less than or equal to $10^{-6}$.

Table 2. Size and material properties of inverter parts.

Figure 5. Linearized waveform of voltage and current [17].

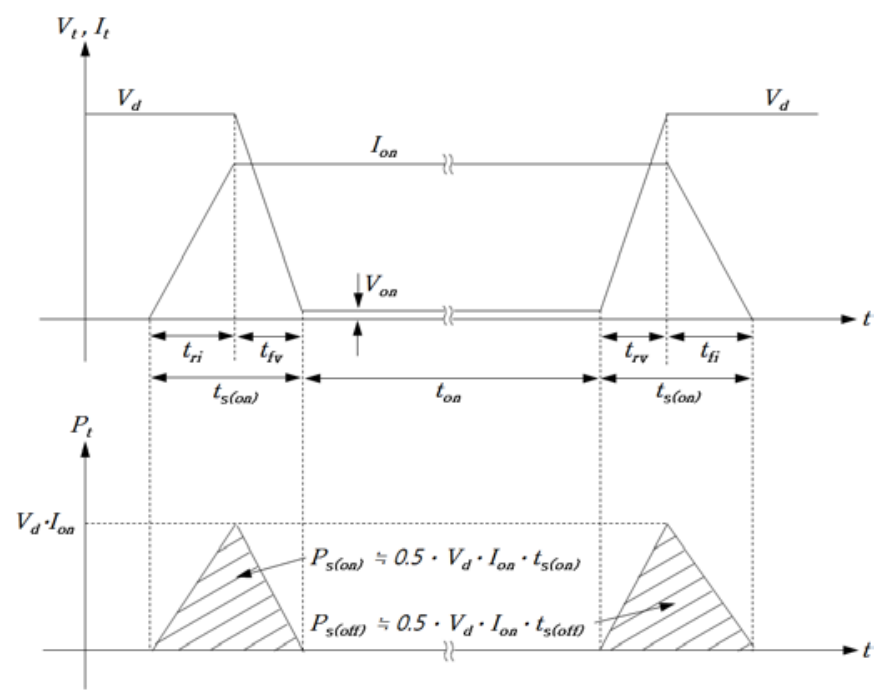




\section{Experimental Setup and Data Reduction}

Figure 6 shows the prototypes of the ISG motor and inverter.

Figure 6. Prototypes of ISG motor and inverter: (a) air-cooled motor; and (b) liquid-cooled inverter.

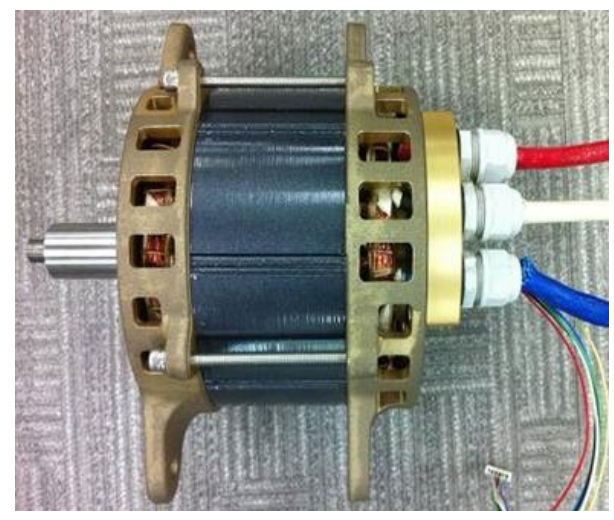

(a)

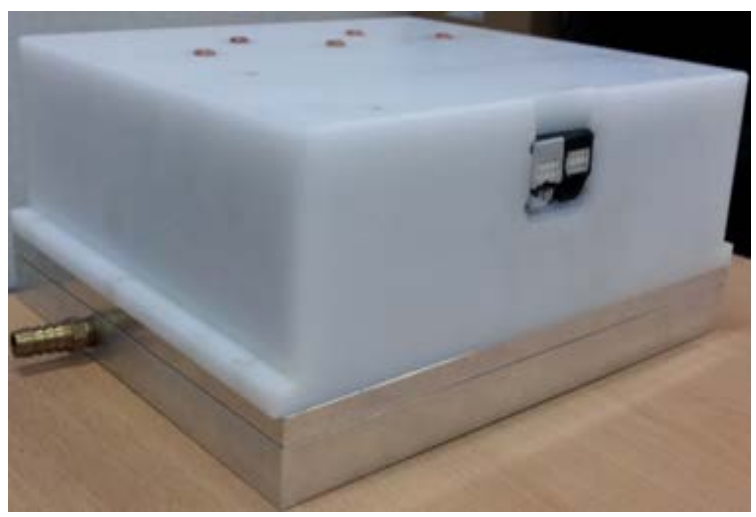

(b)

Figure 7 shows the design of an experimental apparatus for measuring the thermal performance of the motor and the inverter. The schematic diagram illustrates a motor dynamo and jig for installation, prototypes of the ISG motor and inverter, a controller and measuring instrument, etc. The temperature was measured at the coil ends in the motor, and at the MOSFETs, metal PCBs, and cold plates in the inverter. T-type thermocouples (copper-constantan) were installed at each surface position to measure the temperature, and the temperature was considered saturated when temperature changes were within $\pm 0.25^{\circ} \mathrm{C}$ for $10 \mathrm{~min}$.

Figure 7. Experimental apparatus of ISG motor and inverter.

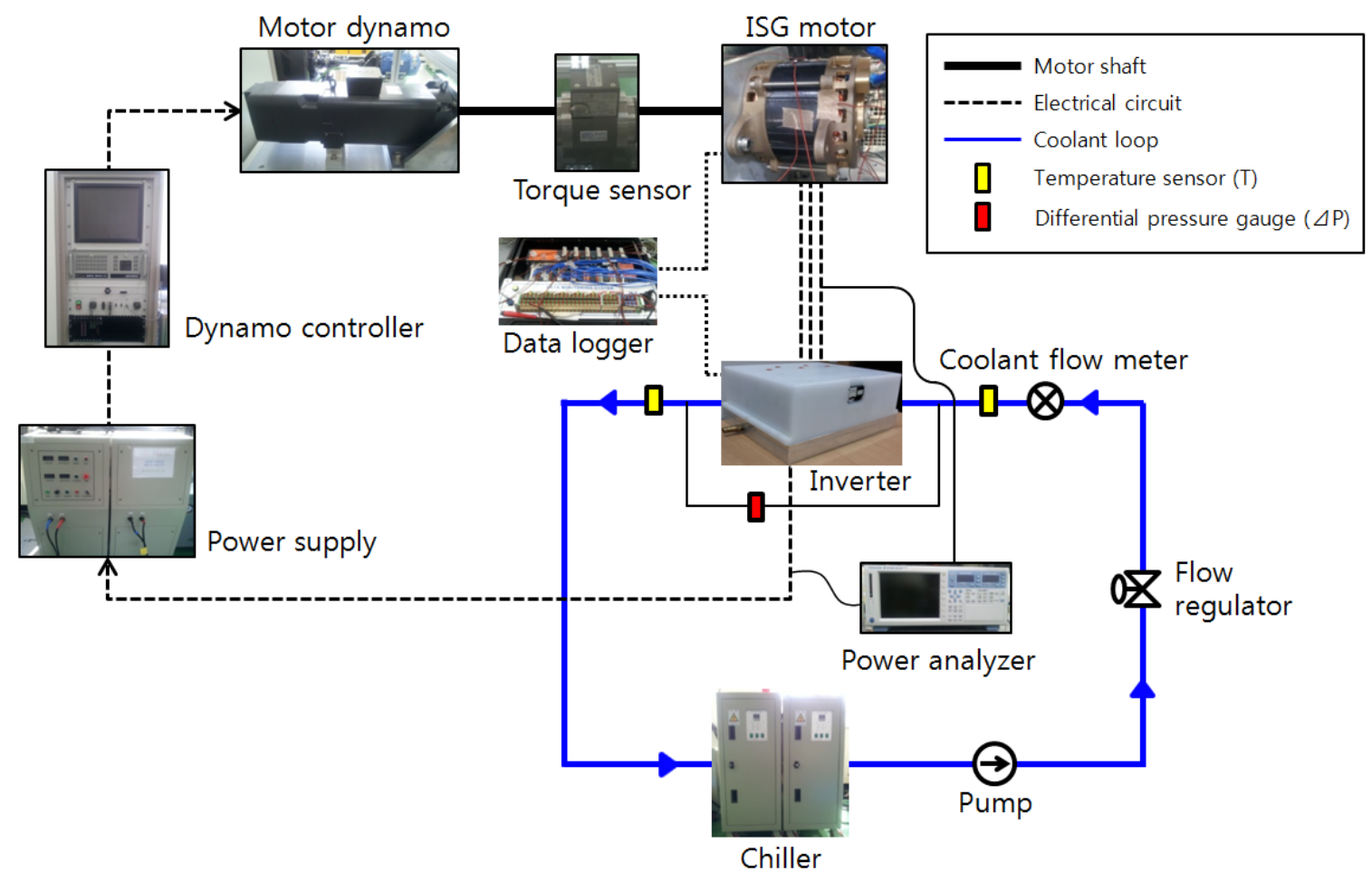


The thermal performance was measured under driving conditions of the ISG motor, meaning it is generating electricity at $7000 \mathrm{rpm}, 7.5 \mathrm{Nm}$, and a current of $150 \mathrm{~A}$ is flowing in the inverter. The efficiencies of the ISG motor and inverter are about $90.6 \%$ and $93.5 \%$, respectively. Such conditions for experiments are the same as the boundary conditions listed in Table 1 . In addition to the motor experiments, which were carried out with the outdoor temperature of $25{ }^{\circ} \mathrm{C}$, inverter experiments to evaluate the heat transfer performance with respect to changes in the coolant temperature $\left(45^{\circ} \mathrm{C}\right.$ to $\left.65^{\circ} \mathrm{C}\right)$ and the coolant flow $(2 \mathrm{~L} / \mathrm{min}$ to $6 \mathrm{~L} / \mathrm{min}$ ) were conducted.

Table 3 lists the specifications of the thermal performance test equipment on the ISG motor and inverter. The temperatures of the motor and inverter were measured using T-type thermocouples with an uncertainty of $\pm 0.1^{\circ} \mathrm{C}$. The coolant flow rate was precisely measured using a Coriolis flow meter (Oval, Japan) located at the inlet of the inverter with an uncertainty of $\pm 0.1 \%$. Differential pressure gauge with an uncertainty of $\pm 0.1 \%$ and the capability to measure a pressure drop of up to 1 bar were installed at the inlet and outlet of the inverter.

Table 3. Specifications of test equipment.

\begin{tabular}{ccc}
\hline Components & Model & Specifications \\
\hline Thermocouples & T-type & $-200 \sim 400{ }^{\circ} \mathrm{C}\left( \pm 0.1{ }^{\circ} \mathrm{C}\right)$ \\
\hline Differential pressure gauge & Honeywell, Morristown, NJ, USA & $33 \mathrm{kPa}( \pm 0.01 \%)$ \\
\hline Coolant flow meter & Coriolis-type & $10 \mathrm{~L} / \mathrm{min}( \pm 0.1 \%)$ \\
\hline Data logger & Gantner, Darmstadt, Germany & E. Gate IP $(\mathrm{V} 3)(2.93 \mathrm{~W} @ 12.06 \mathrm{~V})$ \\
\hline Motor dynamometer & Siemens, Berlin, Germany & $60 \mathrm{~kW} / 9,000 \mathrm{rpm} / 600 \mathrm{Nm}$ \\
\hline Torque transducer & $\begin{array}{c}\text { Hottinger Baldwin Messtechnik, } \\
\text { Darmstadt, Germany }\end{array}$ & $20 \mathrm{Nm}( \pm 0.1 \%)$ \\
\hline Motor speed sensor & Hottinger Baldwin Messtechnik & $12,000 \mathrm{rpm}( \pm 0.01 \%)$ \\
\hline Power analyzer & Yokogawa, Tokyo, Japan & $15 \sim 1,000 \mathrm{~V}( \pm 0.02 \%)$ \\
\hline
\end{tabular}

\section{Results and Discussion}

\subsection{Thermal Characteristics of the Motor}

Table 4 lists the average volumetric temperatures of the main parts of the ISG motor under different motor speeds and ambient temperature conditions. As evidenced in the table, the maximum coil temperatures were $76.1{ }^{\circ} \mathrm{C}$ and $158.5{ }^{\circ} \mathrm{C}$ for the normal and harsh high-temperature conditions, respectively. As the outdoor temperature increased from $25{ }^{\circ} \mathrm{C}$ to $95{ }^{\circ} \mathrm{C}$, the coil temperature of the air-cooled motor increased by about $82{ }^{\circ} \mathrm{C}$ due to increased heat generation in the motor. When the temperature of the engine room in a $\mathrm{HEV}$ is $95^{\circ} \mathrm{C}$, the maximum coil temperature is $41.5^{\circ} \mathrm{C}$ below the temperature limit of the $\mathrm{N}$-type coil insulator, which is about $200{ }^{\circ} \mathrm{C}$. However, $158.5^{\circ} \mathrm{C}$ is adequate given that the temperature at the motor when controlling driving is about $160{ }^{\circ} \mathrm{C}$ in general. This correlation should be taken into account when altering the power density. 
Table 4. Temperature values of each motor part at different motor speeds and ambient temperatures.

\begin{tabular}{|c|c|c|c|}
\hline \multirow{2}{*}{ Motor part } & \multicolumn{3}{|c|}{ Vol. temp. $\left({ }^{\circ} \mathrm{C}\right)$} \\
\hline & $@ 25^{\circ} \mathrm{C}, 7,000 \mathrm{rpm}$ & $\left(25^{\circ} \mathrm{C}, 15,000 \mathrm{rpm}\right.$ & (a) $95^{\circ} \mathrm{C}, 7,000 \mathrm{rpm}$ \\
\hline Flange & 63.5 & 60.4 & 142.7 \\
\hline Stator core & 74.6 & 73.4 & 156.7 \\
\hline Coil & 76.1 & 73.1 & 158.5 \\
\hline Front bearing & 59.5 & 59.2 & 137.1 \\
\hline Rear bearing & 63.7 & 67.5 & 140.2 \\
\hline Rotor core & 56.5 & 53.7 & 133.4 \\
\hline Shaft & 56.8 & 55.2 & 133.5 \\
\hline Magnet & 56.7 & 53.9 & 133.7 \\
\hline Bracket & 67.2 & 65.2 & 145.9 \\
\hline
\end{tabular}

Figure 8 describes how the heat values converge on the coil and the stator core by measuring the temperature distribution of the motor. Specifically, it shows how heat is released via the cooling fans at both ends of the motor. The bearing in Figure $8 \mathrm{~b}$ generates heat that is due to mechanical losses, including friction and wind losses; the amount of heat is small and the effects are negligible given that the heat is transferred to other components.

Figure 8. Temperature contours $\left({ }^{\circ} \mathrm{C}\right)$ of ISG motor with an ambient temperature of $25^{\circ} \mathrm{C}$ and a motor speed of $7000 \mathrm{rpm}$ : (a) radial-cross section; and (b) axial-cross section.

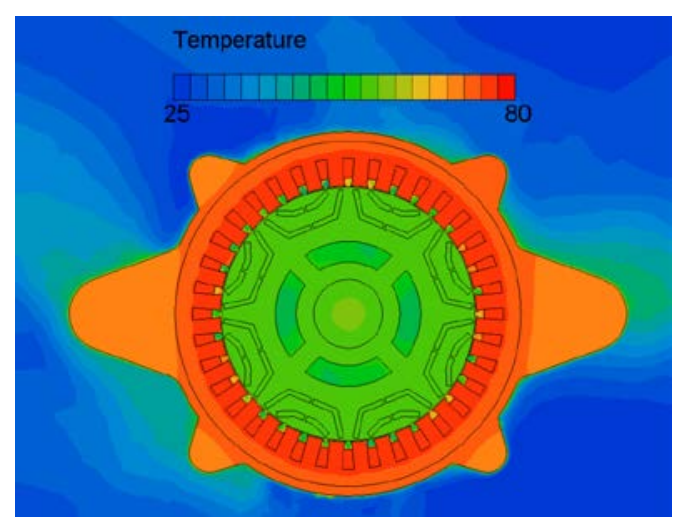

(a)

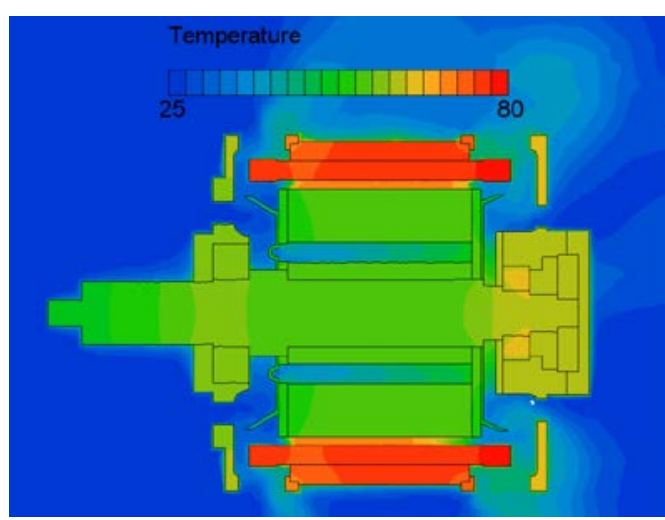

(b)

The heat fluxes among the components or the surface of each component are listed in Table 5. The heat flux is described as (+) and (-) when it flows from right to left or left to right, respectively. Compared to the heat flux caused by forced convection, the heat flux is higher when heat is caused by conduction among the stator core, flange and bracket and when the outdoor temperature is higher. The thermal performance can be improved if the air flow rate produced by the cooling fans is increased. This occurs by reducing the resistance in the inside flow passage and modifying the heat transfer structure by expanding the contact surface between the housing and the motor. 
Table 5. Heat flux of motor surface regions at different motor speeds and ambient temperatures.

\begin{tabular}{|c|c|c|c|}
\hline \multirow{2}{*}{ Surface regions } & \multicolumn{3}{|c|}{ Heat flux $\left(W / m^{2}\right)$} \\
\hline & (a) $25^{\circ} \mathrm{C}, 7,000 \mathrm{rpm}$ & (a) $25^{\circ} \mathrm{C}, 15,000 \mathrm{rpm}$ & (a) $95^{\circ} \mathrm{C}, 7,000 \mathrm{rpm}$ \\
\hline Air vs. flange & 1,498 & 2,338 & 1,845 \\
\hline Air vs. stator core & 1,609 & 2,397 & 2,059 \\
\hline Air $v s$. coil & 2,344 & 3,834 & 3,028 \\
\hline Air vs. shaft & 1,216 & 1,747 & 1,502 \\
\hline Air vs. bracket & 1,149 & 1,916 & 1,502 \\
\hline Air $v s$. rotor core & $-1,069$ & $-1,308$ & $-1,386$ \\
\hline Coil vs. stator core & $-5,027$ & $-3,815$ & $-6,548$ \\
\hline Stator core $v s$. flange & $-28,152$ & $-34,768$ & $-35,879$ \\
\hline Stator core $v s$. bracket & $-20,438$ & $-26,046$ & $-27,563$ \\
\hline
\end{tabular}

Centrifugal fans installed at both ends of the ISG motor cool the motor parts via air flow. Figure 9a demonstrates that the air absorbed by the centrifugal fans reaches the floor of the fans and passes through the exit holes through the blades.

Figure 9. Internal flow of ISG cooling fan @ $25{ }^{\circ} \mathrm{C}, 7000$ rpm: (a) velocity vector (m/s); and (b) pressure contours $(\mathrm{Pa})$.

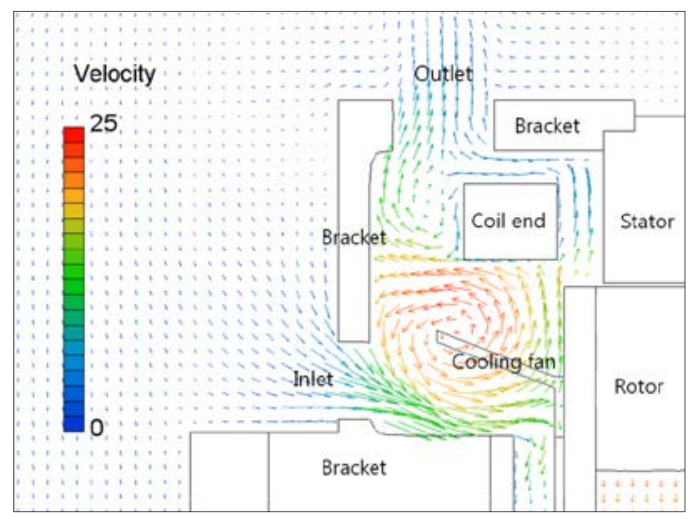

(a)

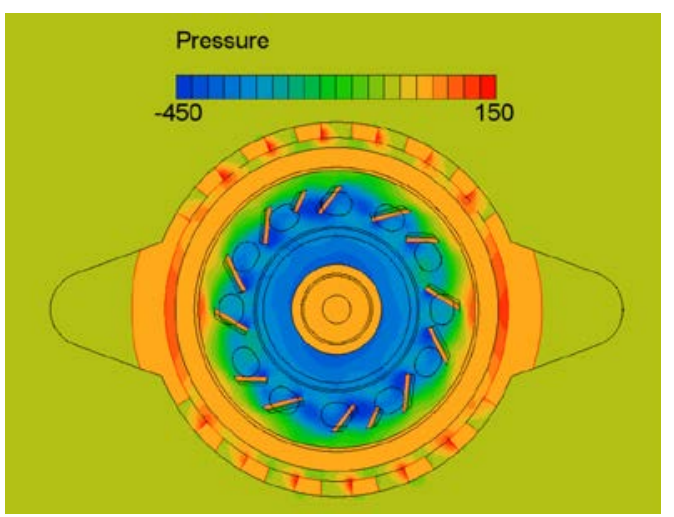

(b)

Kim et al. [18] carried out a study on the thermal performance of the original and modified ISG motors and investigated the effect of various thermal parameters on the cooling as shown in Figure 10. This study improved the heat transfer performance by reducing the recirculation flow, which was accomplished by modifying the shapes of the centrifugal fan blade and altering the hole locations based on the air flow in the ISG motor. In addition, the angle of the outlet holes was altered, and more holes were added to reduce the flow resistance and increase the flow amount, thereby improving the thermal performance. The air flows at the inlet and outlet holes of the motor's cooling fans are in the vertical direction; however, the internal flows are re-circulated around the cooling fans and the coil end, which results in slight flow and pressure losses. Because of the radial outflow structure, the fluid flow caused by the centrifugal fans impacts the housing surface, leading to locally high levels of pressure around the outlet holes, as shown in Figure $9 \mathrm{~b}$. 
Figure 10. Shape of the original and modified ISG motor designs [18]: (a) original model; and (b) modified model.

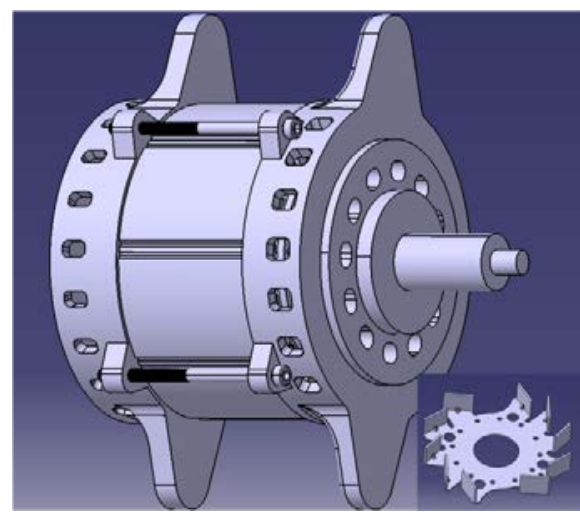

(a)

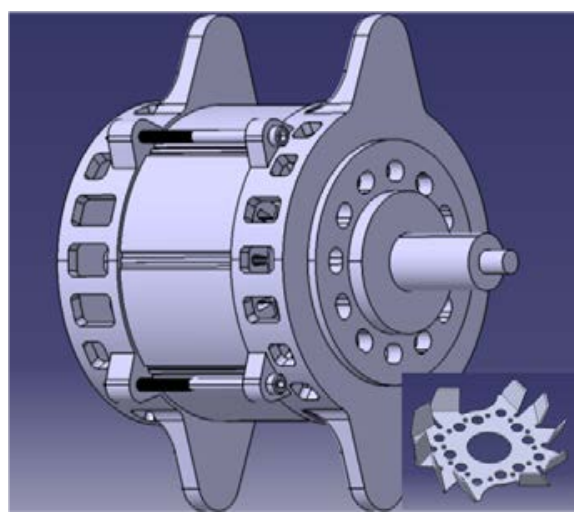

(b)

An analysis was carried out under the same conditions as the dynamo experiment in which the rotation speed was $7000 \mathrm{rpm}$ and the outdoor temperature was set to $25{ }^{\circ} \mathrm{C}$. This analysis used a shape model installed on a jig made from hardened carbon steel (thermal conductivity of $51.9 \mathrm{~W} / \mathrm{m} \mathrm{K}$ ) and incorporated heat loss from the experimental environment of the ISG motor, but excluded heat loss to the axis. In the experiment, in which steady state is defined as changes in the temperature within $\pm 0.25{ }^{\circ} \mathrm{C}$ for $10 \mathrm{~min}$, the temperature of the coil increased to about $72.9{ }^{\circ} \mathrm{C}$, as shown in Figure 11 . These thermal analyses and experiments are considered reliable given that error is $9 \%$, or $4.4{ }^{\circ} \mathrm{C}$, with a temperature increase of $47.9^{\circ} \mathrm{C}$ being the basis for the coil's maximum temperature.

Figure 11. Verification of analysis and experimental results at an increased temperature of $48{ }^{\circ} \mathrm{C}$.

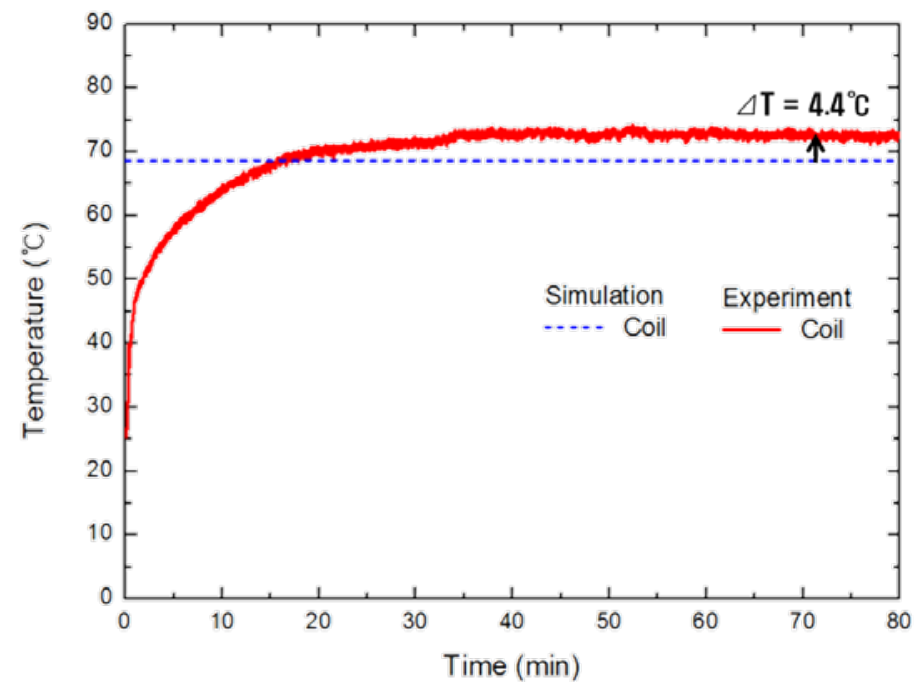

\subsection{Thermal Characteristics of the Inverter}

Figure 12 shows the overall temperature distribution of the ISG inverters, including the MOSFET, metal PCB, and cold plate, for the standard condition with a coolant flow rate of $4 \mathrm{~L} / \mathrm{min}$ and a coolant temperature of $65{ }^{\circ} \mathrm{C}$. The temperature differences among the modules were shown to be within $1{ }^{\circ} \mathrm{C}$ through the temperature distribution of the power modules. 
Figure 12. Temperature contours of ISG inverter: (a) side view; and (b) top view.

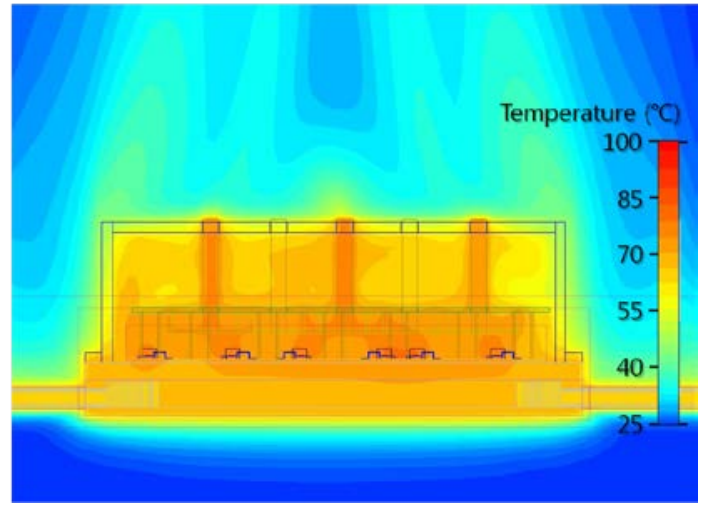

(a)

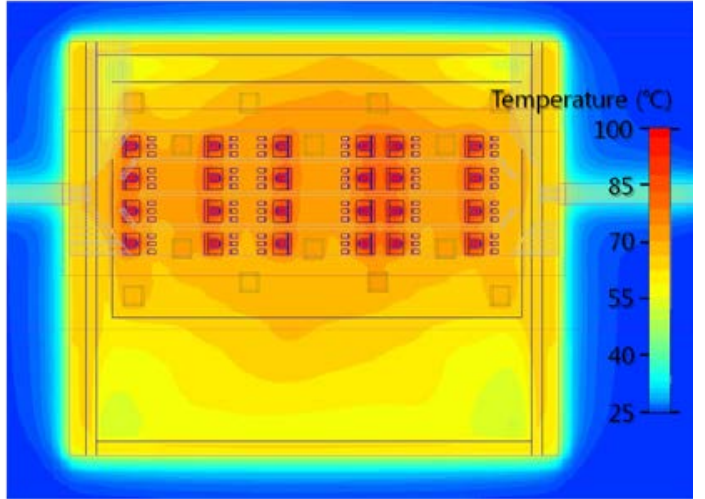

(b)

Table 6 indicates that under the standard conditions, the maximum temperature was about $96.8{ }^{\circ} \mathrm{C}$ at the MOSFET chips, which are a source of high heat generation. This is significantly lower than the temperature limit of $125{ }^{\circ} \mathrm{C}$ [16]; however this design includes the fact that the actual worst driving conditions involve a coolant temperature far higher than the maximum temperature in the experiment.

Table 6. Temperature values of each inverter part.

\begin{tabular}{ccc}
\hline Inverter part & Components & Vol. temp. $\left({ }^{\circ} \mathbf{C}\right) @ 65^{\circ} \mathbf{C}, \mathbf{4 ~ \mathbf { ~ } / \mathbf { m i n }}$ \\
\hline \multirow{2}{*}{ MOSFET } & Chip & 96.8 \\
\cline { 2 - 3 } & Case & 87.0 \\
\hline Metal PCB & - & 70.2 \\
\hline Cold plate & - & 68.6 \\
\hline
\end{tabular}

To validate the inverter analysis model, thermal performance experiments were conducted under different coolant conditions. The results in Figure 13 show that under the standard condition of a coolant flow and temperature of $4 \mathrm{~L} / \mathrm{min}$ and $65{ }^{\circ} \mathrm{C}$, respectively, the temperature increased by about $19.3{ }^{\circ} \mathrm{C}$ in the MOSFET case; the error in the case is $16 \%$, or $3.1{ }^{\circ} \mathrm{C}$. Under various driving conditions, the experimental results were similar to the model results, meaning that the inverter model is reliable. When Zhang et al. [19] assessed the heat transfer performance with respect to the flow structure of coolant IGBT modules, the temperature difference between the experiment and the model analysis was about $10^{\circ} \mathrm{C}$. Compared with the total heat generation of $185.2 \mathrm{~W}$, which was used in the model analysis, the heat released via the coolant in the cold plates was approximately $89 \%$ of that amount, i.e., $164.7 \mathrm{~W}$. When the amount of coolant increased from $2 \mathrm{~L} / \mathrm{min}$ to $6 \mathrm{~L} / \mathrm{min}$, the MOSFET temperature decreased by $3.3{ }^{\circ} \mathrm{C}$. When the coolant temperature was reduced from $65{ }^{\circ} \mathrm{C}$ to $45{ }^{\circ} \mathrm{C}$, the MOSFET temperature decreased by $19.1{ }^{\circ} \mathrm{C}$. This indicates that coolant temperature is more influential than the coolant flow rate on the inverter's heat dissipation. If the coolant is at $100{ }^{\circ} \mathrm{C}$ in an actual driving situation, the temperature of the MOSFET case would be calculated as $121{ }^{\circ} \mathrm{C}$ in the model analysis and $113{ }^{\circ} \mathrm{C}$ in the experiment. The pressure drops in the coolant flow passage would increase from $896 \mathrm{~Pa}$ to $6254 \mathrm{~Pa}$ with respect to the coolant flow rate. 
Figure 13. Temperature variations with respect to different parameters: (a) variation in temperature with respect to coolant flow rate; and (b) variation in temperature with respect to coolant temperature.

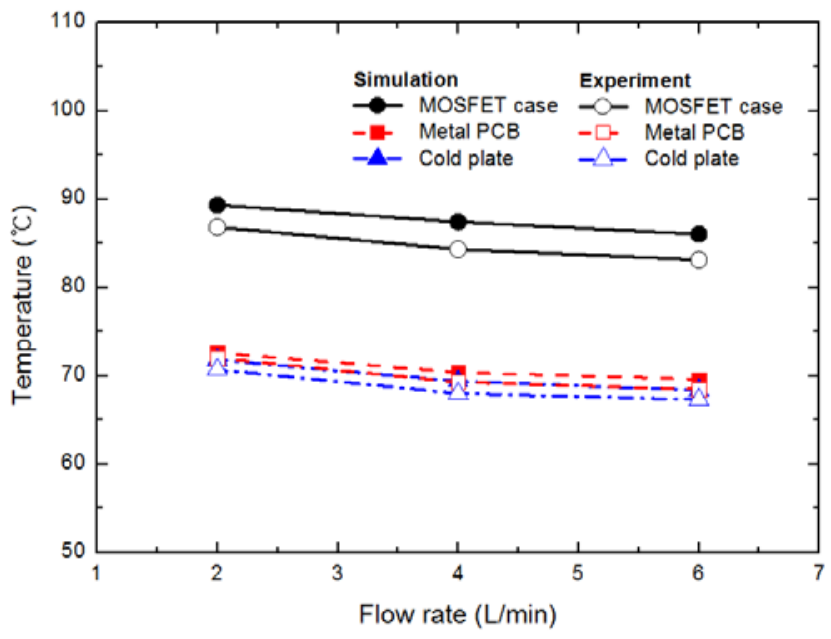

(a)

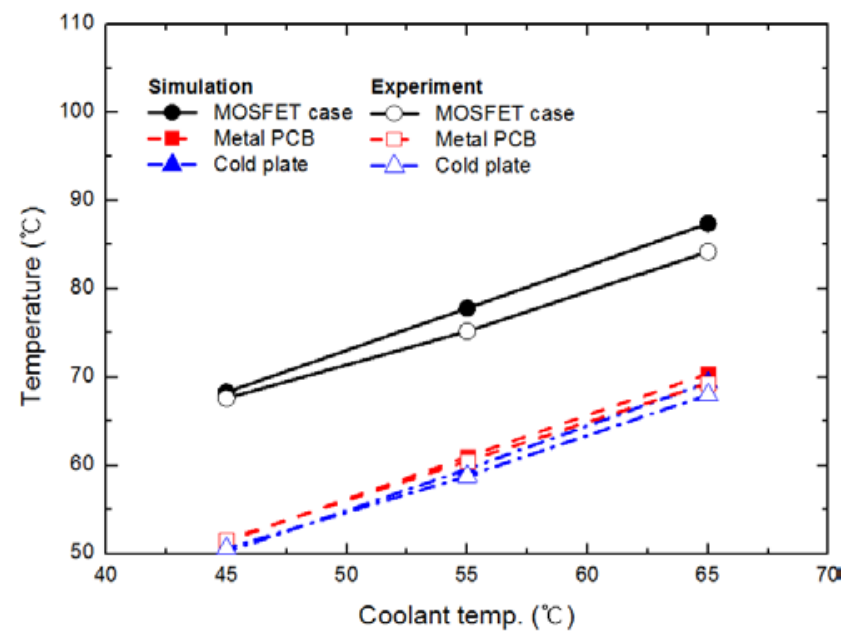

(b)

Figure 14 shows the effects of the inlet and outlet guide lengths of a cold plate on the internal flow velocity and the uniformity of the flow distribution. In the base model, the flow velocity was high in the middle channels, and as the flow rate increased, the flow reached the outlet hole surface, resulting in high levels of recirculation. Meanwhile, this study determined that the heat transfer performance improved when the guide length was $6 \mathrm{~mm}$ longer than that of the base model. With this length increase, the pressure drop in the coolant flow passage decreased by about $90 \mathrm{~Pa}$, and the MOSFET chip temperature decreased by about $0.4{ }^{\circ} \mathrm{C}$ under the coolant flow of $4 \mathrm{~L} / \mathrm{min}$.

Figure 14. Velocity contours at inverter cooling channels: (a) $2 \mathrm{~L} / \mathrm{min}$ (base guide plate); (b) $2 \mathrm{~L} / \mathrm{min}$ (modified guide plate); (c) $4 \mathrm{~L} / \mathrm{min}$ (base guide plate); (d) $4 \mathrm{~L} / \mathrm{min}$ (modified guide plate); (e) $6 \mathrm{~L} / \mathrm{min}$ (base guide plate); and (f) $6 \mathrm{~L} / \mathrm{min}$ (modified guide plate).

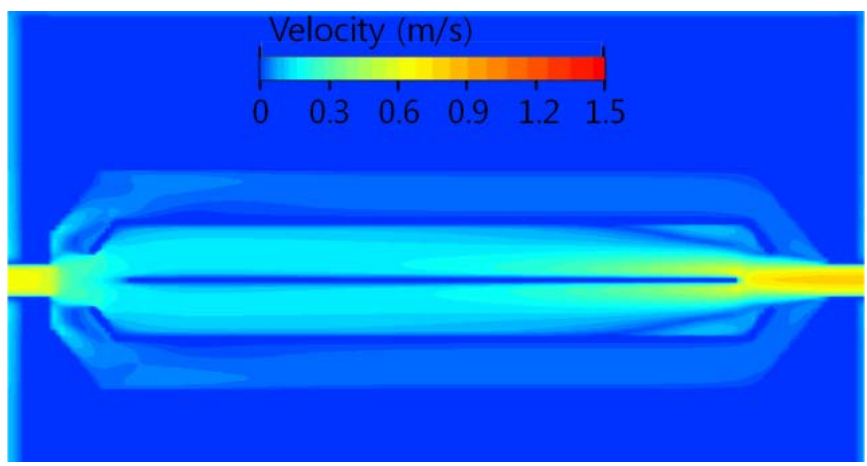

(a)

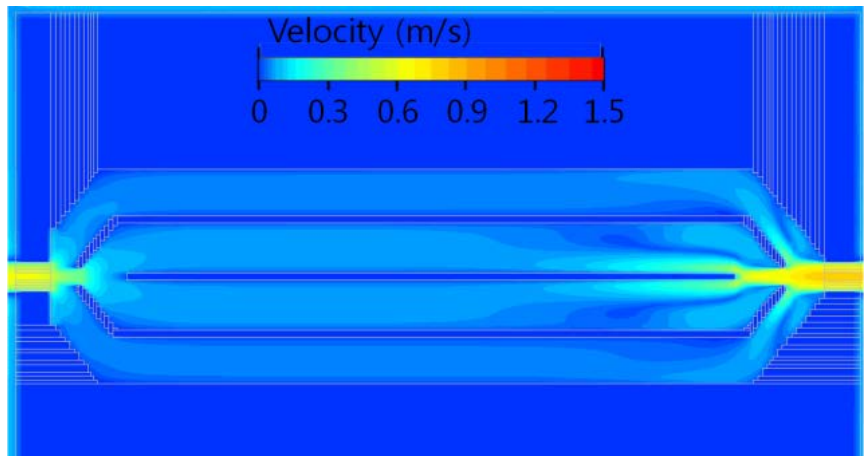

(b) 
Figure 14. Cont.

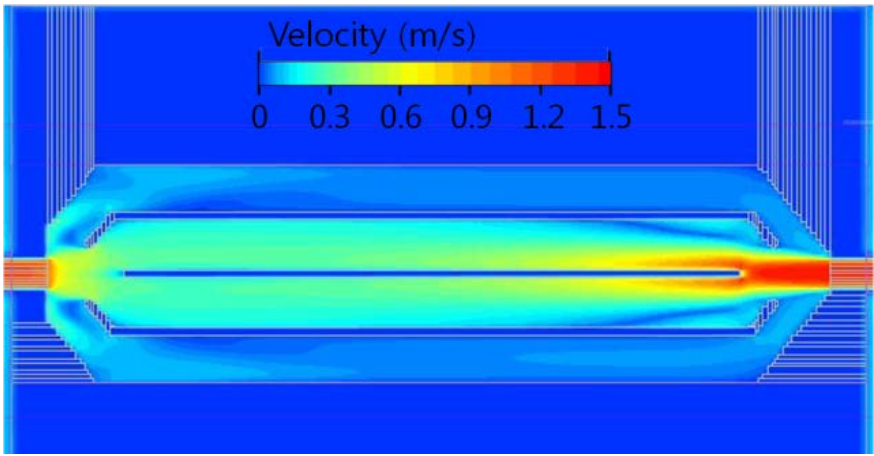

(c)

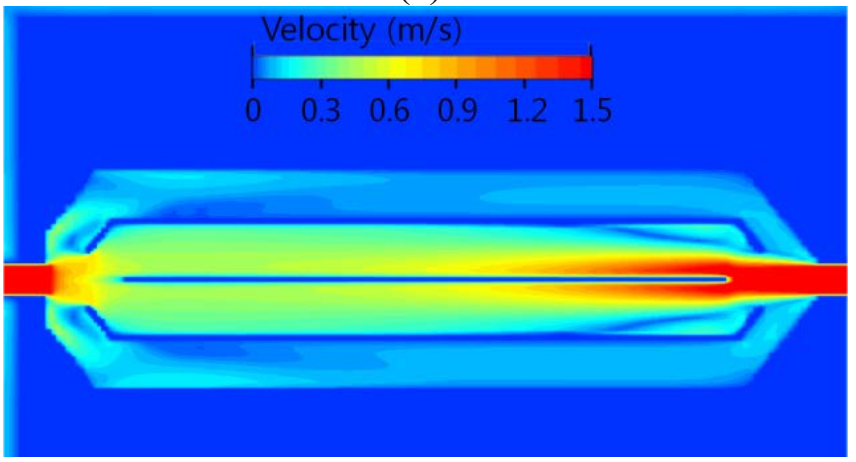

(e)

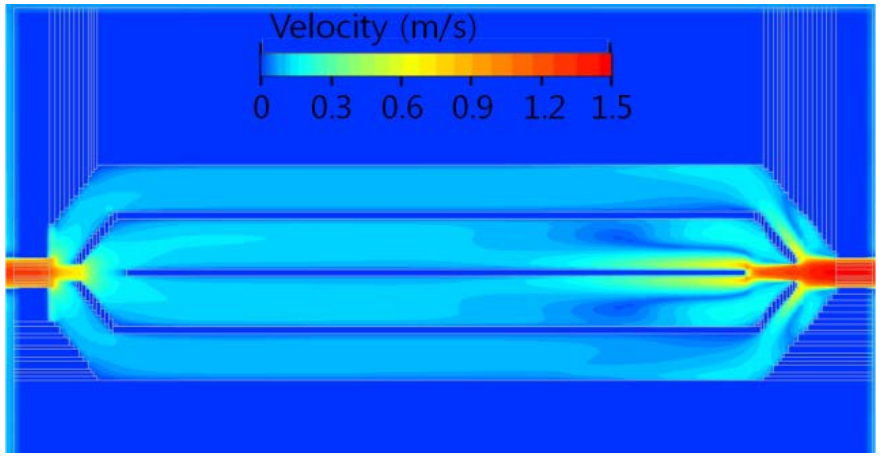

(d)

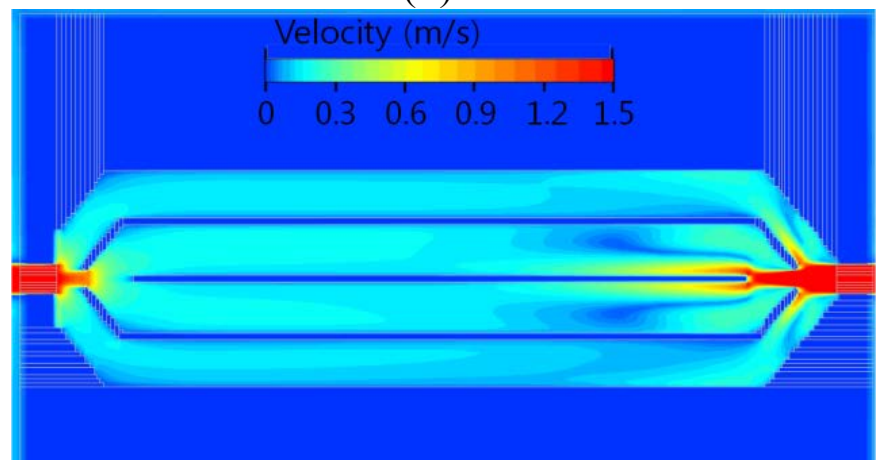

(f)

\section{Conclusions}

This study carried out experiments and model analyses on the heat and fluid flows in an ISG motor and inverter in a HEV, identifying the characteristics of the heat transfer and the temperatures for each component. Based on these results, the thermal performance of the ISG motor and inverter using the proposed cooling structures was found to be sufficient for heat loads under various real driving conditions for a HEV.

In the motor, the coil's maximum temperature was measured under the normal $\left(25^{\circ} \mathrm{C}\right.$ of outside temperature) and harsh high-temperature $\left(95{ }^{\circ} \mathrm{C}\right.$ of outside temperature) conditions. This study determined that the heat generated from the motor is transferred through heat transfer paths, to the flange and the bracket by cooling fans and is released by forced convection. If the outdoor temperature is $95^{\circ} \mathrm{C}$, the coil's temperature increases up to $158.5^{\circ} \mathrm{C}$. Because the maximum allowable temperature is $200{ }^{\circ} \mathrm{C}$, there is still a buffer of $41.5^{\circ} \mathrm{C}$. This result should be taken into account if the power density were to change.

This study also determined that the MOSFET chips, a main region for heat generation in the inverter, were heated up to $96.8^{\circ} \mathrm{C}$ under a coolant flow rate of $4 \mathrm{~L} / \mathrm{min}$ and a coolant temperature of $65{ }^{\circ} \mathrm{C}$, which is far lower than the allowable limit of $125^{\circ} \mathrm{C}$. In addition, the coolant temperature more heavily influenced the heat dissipation than the coolant flow rate. By increasing the inlet/outlet blade guide size by $6 \mathrm{~mm}$ on cold plates, both the backward flow and flow distribution issues were resolved.

Through the temperature measurements and the examination of the model's validity, this study developed an analysis model for the motor and inverter, which confirmed that the results of the thermal analysis were reliable. To design a better ISG motor and inverter with a higher power density and 
smaller size, we will continue studying to discover methods for reducing the heat resistance and optimizing the cooling structure.

\section{Acknowledgments}

This study was carried out as a part of the Industrial Source Technology Development Program sponsored by the Ministry of Knowledge Economy. Additionally, the support from the Komotek Company is greatly appreciated.

\section{Conflicts of Interest}

The author declares no conflict of interest.

\section{References}

1. Yang, F.; Gao, G.; Ouyang, M.; Chen, L.; Yang, Y. Research on a diesel HCCI engine assisted by an ISG motor. Appl. Energy 2013, 101, 718-729.

2. Bitsche, O.; Gutmann, G. Systems for hybrid cars. J. Power Sources 2004, 127, 8-15.

3. Simopoulos, G.N.; MacBain, J.A.; Schneider, E.D.; Wingeier, E.W. Fuel Economy Improvements in an SUV Equipped with an Integrated Starter Generator. In Proceedings of the SAE International Truck \& Bus Meeting \& Exhibition, Chicago, IL, USA, 12-14 November 2001.

4. Lee, G.; Choi, G.; Choi, W. Design considerations for low voltage claw pole type integrated starter generator (ISG) systems. J. Power Electron. 2011, 11, 527-532.

5. Xue, Y.; Ronning, J. Design and testing of a belt-driven induction starter-generator. IEEE Trans. Ind. Appl. 2002, 38, 1525-1533.

6. Kimotho, J.; Hwang, P. Thermal management of electric vehicle BLDC motor. SAE Tech. Pap. 2011, doi:10.4271/2011-28-0134.

7. Li, H.M. Flow driven by a stamped metal cooling fan-Parametric study on blade angles. Eng. Appl. Comput. Fluid Mech. 2010, 4, 222-236.

8. Mallik, S.; Ekere, N.; Best, C.; Bhatti, R. Investigation of thermal management materials for automotive electronic control units. Appl. Therm. Eng. 2011, 31, 355-362.

9. Bennion, K.; Kelly, K. Rapid Modeling of Power Electronics Thermal Management Technologies. In Proceedings of the IEEE Vehicle Power and Propulsion Conference (VPPC), Dearborn, MI, USA, 7-10 September 2009; pp. 622-629.

10. Chen, K.; Ahmed, S.; Maly, D.; Parkhill, S.; Flett, F. Comparison of Thermal Performance of Different Power Electronics Stack Constructions. In Proceedings of the SAE Future Car Congress, Arlington, VA, USA, 3-5 June 2002.

11. Tamai, G.; Jeffers, M.; Lo, C.; Thurston, C.; Tarnowshy, S.; Poulos, S. Development of the Hybrid System for the Saturn VUE Hybrid. In Proceedings of the SAE World Congress \& Exhibition, Detroit, MI, USA, 3-6 April 2006.

12. SC/Tetra Version 7 User's Guide Solver Reference; Software Cradle Co., Ltd.: Osaka, Japan, 2007.

13. MotorPro Version 2.6.B User's Guide Solver Reference; Komotek: Sungnam, Korea, 2004. 
14. Alshamani, K. Equations for Physical Properties of Automotive Coolants. In Proceedings of the SAE World Congress \& Exhibition, Detroit, MI, USA, 3-6 March 2003.

15. FloTHERM Version 9.3 Introductory Training for V9; Mentor Graphics Corporation: Wilsonville, OR, USA, 2012.

16. Boukhanouf, R.; Haddad, A. A CFD analysis of an electronics cooling enclosure for application in telecommunication systems. Appl. Therm. Eng. 2010, 30, 2426-2434.

17. Maniktala, S. Switching Power Supplies A to Z; Elsevier Inc.: Waltham, MA, USA, 2006.

18. Kim, D.G.; Kim, S.C. An analysis study for thermal design of ISG (integrated starter generator) for hybrid electric vehicle. Trans. Korean Soc. Automot. Eng. 2013, 21, 120-127.

19. Zhang, Y.P.; Yu, X.L.; Feng, Q.K.; Zhang, R.T. Thermal performance study of integrated cold plate with power module. Appl. Therm. Eng. 2009, 29, 3568-3573.

(C) 2013 by the authors; licensee MDPI, Basel, Switzerland. This article is an open access article distributed under the terms and conditions of the Creative Commons Attribution license (http://creativecommons.org/licenses/by/3.0/). 